\title{
Aircraft noise and cardiovascular disease near Heathrow airport in London: small area study
}

This Research paper (BMJ 2013;347:f5432, doi:10.1136/bmj. f5432) should have included the following statement in its acknowledgments section of the footnotes: "Hospital Episode Statistics data are copyright (C) 2013, re-used with the permission of the Health and Social Care Information Centre. All rights reserved. The mortality and population data were supplied by the Office for National Statistics (ONS), derived from the national mortality registrations and the Census."

Cite this as: BMJ 2014;348:g3504

๑ BMJ Publishing Group Ltd 2014 